Journal: Applied Microbiology and Biotechnology

\title{
Title:
}

\section{Changes in intracellular metabolite pools during growth of adherent MDCK cells in two different media}

\author{
Authors: Rehberg, M..$^{*}$; Rath, A. ${ }^{1}$; Ritter, J. B. ${ }^{1}$; Genzel, Y. ${ }^{1}$; Reichl, U. ${ }^{1,2}$ \\ ${ }^{1}$ Max Planck Institute for Dynamics of Complex Technical Systems, Magdeburg, Germany \\ 2 Otto-von-Guericke University Magdeburg, Chair of Bioprocess Engineering, Magdeburg, Germany \\ * correspondence to: rehberg@ @mpi-magdeburg.mpg.de, +49 3916110206
}

Keywords: metabolism, glycolysis, citric acid cycle, intracellular metabolite, metabolite dynamics, MDCK 


\section{Abstract}

In bioprocess engineering the growth of continuous cell lines is mainly studied with respect to changes in cell concentration, the resulting demand for substrates, and the accumulation of extracellular metabolites. The underlying metabolic process rests upon intracellular metabolite pools and their interaction with enzymes in form of substrates, products or allosteric effectors. Here, we quantitatively analyze time courses of 29 intracellular metabolites of adherent Madin Darby canine kidney (MDCK) cells during cultivation in a serum-containing and a serum-free medium. The cells, which originated from the same pre-culture, showed similar overall growth behavior and only slight differences in their demand for the substrates glucose, glutamine and glutamate. Analysis of intracellular metabolites, which mainly cover the glycolytic pathway, the citric acid cycle and the nucleotide pools, revealed surprisingly similar dynamics for both cultivation conditions. Instead of a strong influence of the medium, we rather observed a growth phase-specific behavior in glycolysis and in the lower citric acid cycle. Furthermore, analysis of the lower part of glycolysis suggests the well-known regulation of pyruvate kinase by fructose 1,6-bisphophate. The upper citric acid cycle (citrate, cisaconitate, isocitrate) is apparently uncoupled from the lower part ( $\alpha$-ketoglutarate, succinate, fumarate, malate), which is in line with the characteristics of a truncated cycle. Decreased ATP and GTP pools as well as a relatively low energy charge soon after inoculation of cells indicate a high demand for cellular energy and the consumption of nucleotides for biosynthesis. We finally conclude that with sufficient availability of substrates the dynamics of glucose and glutamine/glutamate metabolism is influenced mainly by the cellular growth regime and regulatory function of key enzymes. 


\section{Introduction}

Many biotechnological studies focused on understanding of metabolism to improve product yields and growth performance of cell lines. Of main interest are especially the two major substrates of central carbon metabolism, glucose (GLC) and glutamine (GLN), which are crucial in cellular energy generation as well as in precursor supply for biosynthesis. However, depending on the cell and the process conditions their relative contribution in both cellular functions shows many facets (Barnabé and Butler, 2000; Fitzpatrick et al., 1993; Mckeehan, 1982; Reitzer et al., 1979; Wu and Racker, 1959). GLC is metabolized in glycolysis and subsequently converted to lactate (LAC) instead of being used to generate additional adenosine triphosphate through transfer of pyruvate (PYR) into the citric acid cycle, which is a typical phenomenon of continuous and cancerous cells (Fitzpatrick et al., 1993; Moreno-Sánchez et al., 2007; Neermann and Wagner, 1996), and also applies to Madin Darby canine kidney (MDCK) cells (Sidorenko et al., 2008). In addition, measurement of the maximum in vitro enzyme activity of pyruvate dehydrogenase reveals for MDCK cells a very low capacity for transfer of PYR into the citric acid cycle (Janke et al., 2011). A dysfunction of the citric acid cycle that results in a lowered capacity for metabolite conversion is well-known as Warburg effect (Warburg et al., 1927). However, it is shown for many continuous cell lines that the glucose-specific lactate yield is influenced by the media composition (Genzel et al., 2006; Moreno-Sánchez et al., 2007; Ryll et al., 1994; Sussman et al., 1980), for example by the extracellular levels of amino acids such as GLN and glutamate (GLU) (Baggetto, 1992; Genzel et al., 2005; Häggström et al., 1996). Under limiting 
GLC concentrations, much lower relative LAC release rates are found (Cruz et al., 1999; Häggström et al., 1996). Renner et al. (1972) concluded that a high glycolytic flux easily saturates the synthetic and oxidative pathway and, hence, increases the glucose-specific lactate yield. Due to the high ATP supply provided by glycolysis (Sidorenko et al., 2008; Wahl et al., 2008), GLN is predominantly required as building block in biomass formation, but also allows for a flexible production of ATP through oxidative phosphorylation (Baggetto, 1992; Cruz et al., 1999; Fitzpatrick et al., 1993).

In addition to extracellular substrates, intracellular metabolite levels can modulate enzyme activities in favor of energy generation or biosynthesis (Atkinson and Walton, 1967). Due to their role as substrates, products and allosteric effectors of enzymes, the quantification of changes in intracellular metabolites levels allow obtaining another, more detailed, view on the dynamics of metabolisms. For example, the quantification of intracellular metabolite levels in $\mathrm{CHO}$ cells was used to identify metabolic bottlenecks (Sellick et al., 2011), or to characterize changes in the metabolic profile after adaptation to a new media (Dietmair et al., 2012).

Eventually, the growth status of cells (the growth phase) clearly depends on metabolism but also has an influence on metabolism (Schaub and Reuss, 2008; Suarez and Moyes, 2012) by modulation of enzyme and transporter activities (Levine et al., 2002; Young et al., 2011; Zhang et al., 1999).

So far, however, it still remains to be elucidated to which extent nutrient levels, growth status and allosteric enzyme regulation govern the observed intracellular metabolite dynamics to not only improve the understanding of the metabolic process but also to unravel possible ways to further enhance growth performance and product yield. In this 
study, we analyzed the dynamics of intracellular metabolite pools of the glycolytic, the citric acid, the pentose phosphate, the glycogenesis, and the hexosamine biosynthesis pathway as well as the variation of involved nucleotide pools. Experimental data was obtained from a quantification method established for monitoring 29 intracellular metabolites during growth of adherent MDCK cells in 6-well plates (Ritter et al., 2006; Ritter et al., 2008). To unravel the influence of the media composition on intracellular metabolites, cells from the same pre-culture were grown without preliminary adaptation in a second serum-free media (EpiSerf) with large changes in substrate concentrations. The subsequent discussion focusses on primary changes in metabolite pools and their dependence on growth phases and/or regulatory mechanisms as well as on the influence of the media composition.

\section{Materials and methods}

\section{Cell culture}

Madin Darby Canine Kidney (MDCK) cells (ECACC, \#84121903) were pre-cultured in GMEM (Gibco , \#22100-093), supplemented with 10\% fetal calf serum (Gibco, \#10270106), $2 \mathrm{~g} / \mathrm{L}$ peptone (International Diagnostics Group, \#MC33) and $4 \mathrm{~g} / \mathrm{L} \mathrm{NaHCO}_{3}$ (Roth, \#6885.1), referred to as GMEM-Z. Pre-cultures were either carried out in roller bottles (Greiner Bio-One, \#680XX, experiment depicted in figures with symbol o) or in T-flasks (Greiner Bio-One, \#661160, experiments depicted in figures with symbol $\Delta$ and $\square$ ) at 37 ${ }^{\circ} \mathrm{C}$ and $5 \% \mathrm{CO}_{2}$. The actual experiments were done in parallel 6-well plates (Greiner Bio-One, \#657160) containing 4 mL GMEM-Z or EpiSerf (Gibco, \#10732-022) with an 
average initial cell concentration of about $6 \cdot 10^{5}$ cells/well, cultivated at $37{ }^{\circ} \mathrm{C}$ and $5 \%$ $\mathrm{CO}_{2}$ in an incubator. Three independent cultivations were performed for each cultivation condition (serum-containing, GMEM-Z; serum-free, EpiSerf) with subsequent analytics applied to at least three individual wells per time point.

\section{Cell number and total cell volume}

To remove dead cells and spent medium, cells were washed 3 times with PBS $\left(8 \mathrm{~g} \mathrm{~L}^{-1}\right.$ $\mathrm{NaCl}, 0.2 \mathrm{~g} \mathrm{~L}^{-1} \mathrm{KCl}, 0.2 \mathrm{~g} \mathrm{~L}^{-1} \mathrm{KH}_{2} \mathrm{PO}_{4}, 1.2 \mathrm{~g} \mathrm{~L}^{-1} \mathrm{Na}_{2} \mathrm{HPO}_{4}$ ) and. Subsequently, viable cells were treated with $0.5 \mathrm{mg}$ trypsin $(2.5 \%$ porcine) per well (Gibco, \#27250-018) for 30 min. The remaining viable cells were harvested using a cell scraper. A Vi-Cell TM XR Cell Viability Analyzer (Beckman Coulter) was used for cell counting and measurement of the mean cell diameter (average of the mean cell diameter determined individually for a total number of 100 images per sample). Cell number and cell diameter distribution were used to determine the total cell volume. Cross checking the cell diameters, determined with the Vi-Cell device, with confocal microscopy of stained cells revealed an influence of trypsination (Ritter, 2010). The best match was found for a trypsination time of 30 minutes. Error bars of the total cell volume represent the standard deviation of the mean, and were calculated based on the error propagation law. In a model-based analysis of adherent MDCK cells cultivated in GMEM-Z by Rehberg et al. (2013), the well surface was identified as the main limiting factor of growth. The resulting intermediate growth phase is depicted in subsequent figures as light grey bar (5 $\%-95 \%$ inhibition, $27 \mathrm{~h}-59 \mathrm{~h})$. The black bar marks the interval where the calculated total cell volume reaches $95 \%$ of its final level in all three experiments $(52 \mathrm{~h}-55 \mathrm{~h})$. 


\section{Quantification of extra- and intracellular metabolites}

Concentrations of ammonium $\left(\mathrm{NH}_{4}\right)$, GLC, GLN, GLU, and LAC in the supernatant were quantified as described by Genzel and Reichl (2007) using a Bioprofile 100 plus analyzer (Nova Biomedical, relative standard deviation of the method $1.9-6.4 \%$ (Ritter, 2010)).

For the measurement of intracellular metabolites sample preparation was performed as described in detail by Ritter et al. (2010) using ice cold solutions. In short, the medium of the wells was discarded and cell layers were washed with $0.9 \% \mathrm{NaCl}$ solution. Quenching of metabolic reactions and extraction of metabolites was done by immediate addition of $\mathrm{MeOH} / \mathrm{CHCL}_{3}$ solution (1:1). Quantification of the intracellular metabolites was performed by anion exchange chromatography (BioLC system, Dionex) in combination with mass spectrometry (LC-MS, relative standard deviation of the method $0.7-9.5 \%$ ), as described by Ritter et al. (2006) and Ritter et al. (2008). The absolute amounts of metabolites per well were related to the total cell volume at respective times of cultivation. To reduce the error, regression analysis was used to determine a calculated total cell volume based on sigmoid functions (fitted with MATLAB ${ }^{\circledR}$ using the curve fitting toolbox; data not shown). The limit of quantification was related to the calculated total cell volume and is hence time dependent.

\section{Results}

MDCK cells, from the same pre-culture in serum-containing GMEM-Z medium, were seeded into a new well with either GMEM-Z or serum-free EpiSerf medium to unravel the influence of different media on cell growth and to characterize changes in metabolite 
pools. First, we describe the cell growth as well as the uptake and release of extracellular metabolites of the EpiSerf cultures in comparison to the GMEM-Z cultures. Afterwards, the dynamics of the intracellular metabolite pools is described. A more detailed, modelbased analysis of MDCK cell growth in GMEM-Z is given elsewhere (Rehberg et al. (2013)).

\section{Cell growth and extracellular metabolites}

The time course of cell numbers of both cultures (Fig. 1a) showed in mean a maximum specific growth rate of $0.035 \mathrm{~h}^{-1}\left(27 \mathrm{~h}-54 \mathrm{~h}\right.$ in EpiSerf cultures) and of $0.040 \mathrm{~h}^{-1}(20 \mathrm{~h}-$ $52 \mathrm{~h}$ in GMEM-Z culture) for the three experiments $(\Delta, \square, \circ)$ based on logarithmic regression. The mean cell diameter was initially $(t=0)$ lower and the maximum cell diameter was slightly later achieved in case of the EpiSerf cultures (Fig. 1b). Differences between single experiments regarding the mean cell diameter can be attributed to variations in pre-culture conditions, such as usage of T-flasks or roller bottles and harvest time point of pre-cultures (Rehberg et. al., 2012).

In contrast to the increase in cell numbers, growth in total cell volume (Fig. 1c) occurred at a similar time interval for both media $(6 \mathrm{~h}-46 \mathrm{~h})$ with nearly the same maximum specific growth rate $\left(0.039 \mathrm{~h}^{-1}\right.$ in EpiSerf; $0.040 \mathrm{~h}^{-1}$ in GMEM-Z). At $96 \mathrm{~h}$ and later, the total cell volumes in the EpiSerf cultures reached higher levels of about $10-11 \mu \mathrm{L}$ (GMEM-Z: $7 \mu \mathrm{L}$ ) due to slightly higher mean cell diameters and apparently higher cell numbers with $4 \cdot 10^{6}$ up to $5 \cdot 10^{6}$ cells per well (GMEM-Z: $3 \cdot 10^{6}-4 \cdot 10^{6}$ ).

Both media differ significantly in the initial concentration of GLC, GLN and GLU (Fig. 1 d-f). Nevertheless, only a slight reduction of the total cell volume-specific GLC uptake 
rate for the EpiSerf cultures was found (Table 1). In addition, the total cell volumespecific GLN uptake rates also seem to be lower in EpiSerf cultures, in particular if considering the total consumption of GLN (Fig. 1e). As expected, the GLC and GLN uptake (Fig. 1d,e) was directly correlated with the increase in the total cell volume in the time interval $0-55 \mathrm{~h}$ (Fig. 1c). After the cease of total cell volume growth (black bar), GLC concentration decreased more or less linearly in GMEM-Z indicating cell growth inhibition (stationary growth phase, $55-200$ h, Fig. 1d). MDCK cells require no or only marginal amounts of GLN during stationary growth phase (Baggetto, 1992; Rehberg et al., 2013), and the linear decrease of GLN after $59 \mathrm{~h}$ resulted mainly from spontaneous decomposition of GLN in GMEM-Z medium $\left(0.0036 \mathrm{~h}^{-1}\right.$, Fig. 1e, (Bock et al., 2009; Glacken et al., 1988)) and loss of water (water evaporation rate constant about $2.75 \times 10^{-6}$ $\mathrm{L} \mathrm{h}^{-1}$ ). However, in EpiSerf cultures GLC was depleted after cells reached the stationary growth phase (72 h, Fig. 1d). The GLN concentration was constant during stationary growth phase (Fig. 1e). In experiment $\circ$ of the EpiSerf culture, higher initial GLN levels were measured than in the other two experiments $\Delta$ and $\square$. The uptake of GLU (Fig. 1f) started shortly after onset of cell growth inhibition (light grey field) and lasted until GLU was depleted during the stationary growth phase (GMEM-Z: 60 h, EpiSerf: 96 h). The uptake rate of GLU was slightly lower in EpiSerf cultures compared to GMEM-Z but the uptake lasts longer due to higher initial GLU levels. In glycolysis, GLC is converted to PYR and the subsequent conversion to LAC is catalyzed by the enzyme lactate dehydrogenase. Correlated with the drop in GLC uptake, LAC accumulation (Fig. 1g) ceased after about $72 \mathrm{~h}$ of cultivation in EpiSerf medium while in GMEM-Z a linear increase until the end of the cultivation was observed. Deamination of GLN to GLU and 
the conversion of GLU to $\alpha$-ketoglutarate ( $\alpha \mathrm{KG})$, catalyzed by glutamate dehydrogenase, both result in a release of ammonium $\left(\mathrm{NH}_{4}\right.$, Fig. 1 h). $\mathrm{NH}_{4}$ levels showed a linear increase during cultivation, even at late time points where GLN and GLU were not consumed. In GMEM-Z cultures, the spontaneous decomposition of GLN may explain the increase. In EpiSerf cultures, however, this increase most likely reflects the consumption of other amino acids as GLN was not decreasing. The energy charge $(\mathrm{ATP}+0.5 \mathrm{ADP}) /(\mathrm{ATP}+\mathrm{ADP}+\mathrm{AMP})$ showed values above 0.8 over the complete time course of cultivation (Fig. 1i), which is within the typical limits found for mammalian cells (Ballard, 1970).

\section{Glycolysis}

During cultivation in GMEM-Z and EpiSerf, the intermediates glucose 6-phosphate (G6P, Fig. 2a), fructose 6-phosphate (F6P, Fig. 2b) and fructose 1,6-bisphosphate (F16BP, Fig. 2c), which form the upper part of glycolysis, showed a strong increase up to $24 \mathrm{~h}$ post inoculation. With the onset of cell growth inhibition until the time point of full growth inhibition (light grey field) all three intermediates decreased in concentration and remained in the subsequent stationary growth phase at a more or less constant levels. The decrease in levels of glycolytic intermediates during the transition to stationary growth phase was also observed for CHO cells (Sellick et al., 2011). With depletion of extracellular GLC in EpiSerf medium, the measured levels of G6P and F16BP were lower than the limit of quantification of our validated assay and were thus slightly different to that of the GMEM-Z culture. 
In the lower part of glycolysis, 3-phosphoglycerate (3PG) as well as phosphoenolpyruvate (PEP) showed an increase in concentration until $48 \mathrm{~h}$, which corresponded to the cease of total cell volume growth (Fig. 2d-e). In the EpiSerf culture, the time courses of PEP seemed to follow the peak behavior of 3PG concentrations. In GMEM-Z, the time series of PEP was rather similar to PYR as both increased to their maximum concentrations at about $24 \mathrm{~h}$ and remained constant afterwards (Fig. 2e-f). Albeit the fact that cells of both culture media originated from the same pre-culture, intracellular PYR concentrations of the cells in EpiSerf cultures were initially higher with a fast dropping to concentrations lower than in GMEM-Z cultures.

\section{Glycogenesis, pentose phosphate pathway and hexosamine biosynthesis pathway}

Possible metabolic branches for the glycolytic intermediate G6P are glycogenesis or the pentose phosphate pathway, which comprises ribose 5-phosphate (R5P). Glycogenesis is initiated by an isomerization of G6P to glucose 1-phosphate followed by a reaction with uridine triphosphate (UTP) to uridine diphosphate glucose (UDPGlc). Afterwards glycogen is produced and serves as energy storage.

Time courses of both, UDPGlc as well as R5P, suggested a strong correlation with dynamics of G6P and the intermediates in upper glycolysis in general (Fig. 3a-b). Both metabolites increased initially, achieved a maximum at $24 \mathrm{~h}$ and decreased with onset of cell growth inhibition (light grey field) to a stationary level. In the EpiSerf culture, the level of UDPGlc was mostly below that of the GMEM-Z cultures, similar to the intracellular metabolites of the upper glycolytic pathway. 
F6P is used for amination with ammonium as the first step of the hexosamine biosynthesis pathway and, in the end, uridine diphosphate $\mathrm{N}$-acetylglucosamin (UDPGlcNAc) and its stereoisomer uridine diphosphate $\mathrm{N}$-acetylgalactosamine (UDPGalNAc) are produced, which are involved in intracellular signaling as well as glycoprotein and glycolipid synthesis (Ryll et al., 1994). Interestingly, cultivation in the two media resulted in totally different, nearly inverse, time courses of both intracellular metabolites with a maximum for GMEM-Z medium and minimum for EpiSerf medium at 72 h (Fig. 3c-d).

\section{Citric acid cycle}

In MDCK cells, PYR is mainly metabolized to lactate and only minor amounts enter the citric acid cycle by conversion to citrate (CIT) or oxaloacetate (Janke et al., 2010; Sidorenko et al., 2008). However, MDCK cells can also produce oxaloacetate and $\alpha \mathrm{KG}$ from GLU. In the following reactions, $\alpha \mathrm{KG}$ can be converted to oxaloacetate by the lower part of the citric acid cycle while passing the intermediates succinate (SUC), fumarate (FUM) and malate (MAL) and thereby interacting with several enzymes and cofactors (Wahl et al., 2008), e.g. the measured guanosine triphosphate (GTP) and guanosine diphosphate (GDP).

During cultivation, both $\alpha \mathrm{KG}$ and SUC showed a peak-like behavior at about $48 \mathrm{~h}$ (Fig. 4a-b). Unexpectedly, the level of $\alpha \mathrm{KG}$ in experiment $\bigcirc$ was generally higher after the peak compared to experiments $\Delta$ and $\square$, which was not found for other intracellular metabolites. In case of SUC, cells grown in EpiSerf had slightly lower levels. However, FUM and MAL both showed the peak-like behavior at $48 \mathrm{~h}$ more clearly (Fig. 4c-d). 
With the cease of total cell volume growth, the concentration of both metabolites dropped until $72 \mathrm{~h}$ and then remained more or less constant for GMEM-Z medium. In case of the EpiSerf culture, the levels dropped again (at the same time when GLU was depleted), and after $96 \mathrm{~h}$ the intracellular concentrations were lower than those of the GMEM-Z culture. In the upper part of the citric acid cycle, turnover of CIT to isocitrate (ICIT) is catalyzed by aconitase, while cis-aconitate (CAC) is an intermediate during this reaction. However, concentrations of CAC were close to the quantification limit. Clearly, all three metabolites were highly correlated in their dynamics and concentrations decreased over time (Fig. 5a-c). The concentration in EpiSerf cultures was initially higher than that of GMEM-Z cultures. With increasing cultivation time CIT, CAC and ICIT of EpiSerf cultures approached the levels found in GMEM-Z cultures. With depletion of GLC in the EpiSerf culture after $72 \mathrm{~h}$, it seemed that concentration of all three metabolites dropped again.

\section{Nucleotides}

Nucleotides are cofactors for many enzymatic reactions where phosphate groups must not only be transferred for phosphorylation or dephosphorylation reactions but also represent building blocks for biosynthesis.

ATP, adenosine diphosphate (ADP) and adenosine monophosphate (AMP) showed significant changes in concentrations during the time course of cultivations (Fig. 6a-c). Concentrations of ATP increased roughly from $2 \mathrm{mmol} \mathrm{L}^{-1}$ to $4 \mathrm{mmol} \mathrm{L}^{-1}$ at the beginning of cultivation but with large experiment-specific differences, especially in the EpiSerf cultures where experiment o started already with elevated ATP levels. When 
cells entered the stationary growth phase the level of ATP remained high. However, in case of EpiSerf cultures ATP concentrations dropped slightly after about $96 \mathrm{~h}$ while in GMEM-Z cultivations a minor increase towards later time points was noticed. ADP and AMP concentrations were low in general $\left(0.4 \mathrm{mmol} \mathrm{L}^{-1} ; 0.1 \mathrm{mmol} \mathrm{L}^{-1}\right)$ with time courses more or less inverted to the ATP dynamics.

The time series of the guanosines (Fig. 6d-f) were very similar to those of the adenosines but with much lower intracellular concentrations. In case of guanosine monophosphate (GMP, Fig. 6f), the concentration was mostly below the quantification limit but with a trend that might be similar to the AMP dynamics.

The time series of the remaining nucleoside triphosphates, cytidine triphosphate (CTP) and uridine triphosphate (UTP), showed a different behavior compared to ATP and GTP (Fig. 6g, j). Both time courses seemed to correlate with dynamics in upper glycolysis by increasing in concentrations until achieving a maximum at $24 \mathrm{~h}$. With the onset of growth inhibition a drop to their initial levels was observed and both remained constant during stationary growth phase. In contrast to the adenosines, an inverted behavior of diphosphatic or monophosphatic nucleotides to their triphosphatic counterpart was not observed. Cytidine diphosphate (CDP, Fig. 6h), cytidine monophosphate (CMP, Fig. 6i) and uridine diphosphate (UDP, Fig. 6k) started with elevated levels, decreased and remained constant afterwards during stationary growth phase, similarly to the time courses of ADP, AMP or GDP. Uridine monophosphate (UMP) measurements showed a dynamic behavior similar to the UTP dynamics. 


\section{Discussion}

\section{Effect of media on cell growth and uptake rates}

MDCK cells from an identical pre-culture in GMEM-Z medium were seeded into 6-well plates to grow either in GMEM-Z or in EpiSerf medium. Thus, cells inoculated in EpiSerf medium grew without preliminary adaptation and unravel the influence of different, but still sufficient, nutrient levels on metabolism. Both media have substantial differences in the abundance of substrates and amino acids. In accordance to literature, we expected the cells to show clear differences in their growth behavior (Barnabé and Butler, 2000; Kallel et al., 2002; Niklas et al., 2011; Reitzer et al., 1979; Renner et al., 1972; Ryll et al., 1994; Wu and Racker, 1959), e.g. in lag phase, in specific growth rate or in time point of growth limitation by substrates or inhibitors with largely unknown effects on intracellular metabolite pool dynamics.

Interestingly, however, the general growth behavior was very similar. Minor differences were found in a slightly extended delay in cell number increase (about $6 \mathrm{~h}$ ), and in a higher final cell volume of EpiSerf cultures. In both media the cell volume showed exponential growth from the first measurement time point, which fits to observations of Nielsen et al. (1997) for hybridoma cells in "shift up experiments". Osmolality was higher by $60 \mathrm{mOsm} \mathrm{kg}^{-1}$ (Vapro Osmometer 5520) in EpiSerf medium (EpiSerf: 375 mOsm $\mathrm{kg}^{-1}$; GMEM-Z: $320 \mathrm{mOsm} \mathrm{kg}^{-1}$, data not shown) and may explain the lower mean cell diameter in EpiSerf medium after inoculation. Later, cell diameters in EpiSerf medium were slightly larger than in GMEM-Z culture. Another observation was that the total cell volume of later times was on average higher in EpiSerf cultures due to slightly higher final cell numbers and slightly higher mean cell diameters $(t>72 h)$. Missing 
factors for cell attachment of the serum-free EpiSerf medium may contribute to changes in cell morphology, i.e. an increase in cell height in the monolayer. Nevertheless, for the subsequent analysis of the dynamics of intracellular metabolite pools we assume that the overall growth pattern was mostly the same in both media and hence justifies a separation of growth phases according to Fig. 1-6 (5-95\% growth inhibition, light grey; cease of cell volume growth, black bar) for both cultivation conditions.

The decrease in substrate levels as well as the increase in by-product concentrations were qualitatively similar for both media, at least until GLC was depleted (72 h, c.f. Fig. 1). The total cell volume-specific uptake rates, calculated for GLC, GLN and GLU, seemed to be slightly reduced for cells cultivated in EpiSerf medium (although statistically insignificant). From other cells it is known that low substrate concentrations can lead to a reduced cellular uptake and a reduced relative rate of LAC secretion (Cruz et al., 1999; Häggström et al., 1996; Reitzer et al., 1979; Renner et al., 1972). However, as initial GLC levels were clearly not growth-limiting (Cruz et al., 1999; Glacken et al., 1988), it seems that the slight changes in uptake rates for substrates are decreased because of the serum-free medium EpiSerf, as already observed by Genzel et al. (2006). However, in both media a strong GLU uptake with the start of cell growth inhibition was observed which is in agreement with findings for MDCK cells by Genzel et al. (2005). Also LAC production was similar in both media until GLC was depleted $(\mathrm{t}>60 \mathrm{~h})$ in the EpiSerf culture. Interestingly, despite some differences in GLN and GLU uptake in both media, a similar trend in $\mathrm{NH}_{4}$ concentrations was found. Taking into account that MDCK cells in stationary growth phase do not require the uptake of GLN (similarly to cancer cells, (Baggetto, 1992; Rehberg et al., 2013), and GLU was depleted, the linear increase at later 
cultivation times may result from the consumption of other amino acids with corresponding release of $\mathrm{NH}_{4}$ (Genzel et al., 2004).

\section{Comparison of intracellular metabolite concentrations}

To compare intracellular metabolite dynamics of cells grown in two different media, the referencing of metabolic amounts to cell specific volume is preferred (Atkinson, 1969; Purich and Fromm, 1972; Sussman et al., 1980). While this allows an adequate comparison under cell size variations, it assumes an even distribution within the intracellular space (Erlinger and Saier, 1982). Furthermore, it should be considered that quantification of metabolic amounts was a mean value for a cell population and that the cellular metabolism could be influenced by the quenching method, although it lasted only a few seconds and was performed with ice cold solutions. Measuring intracellular metabolite levels during washing with PBS showed a normal operation of central carbon metabolism for 20 seconds under $37^{\circ} \mathrm{C}$ (data not shown) due to remaining substrates on the cellular surface and/or in the inter-cellular space. However, for the following discussion we assume an even distribution of metabolite concentration within the intracellular space and that the measurement of the population reflects the in vivo metabolite concentrations of a single cell.

\section{Regulation of the upper part of glycolysis and associated pathways}

In the cytosol, GLC is captured by phosphorylation which prevents externalization by the glucose transporter GLUT1, GLUT2, GLUT5 or GLUT9, typically present in kidney cells (Levine and Puzio-Kuter, 2010; Moreno-Sánchez et al., 2007; Nelson et al., 1996; 
Takata et al., 1999; Thorens, 1993). Subsequently, major amounts of G6P are converted in glycogenesis, the pentose phosphate pathway and glycolysis to UDPGlc, R5P and F6P, respectively. All three intermediates showed a dynamic correlated with G6P time series, although the various enzyme-catalyzed reactions require different cofactors. Thus, a concerted regulation of these enzymes through the cofactors appears unlikely. Rather, the hexokinase or the GLUT facilitated transport may form a bottleneck that affects these pathways by the G6P production rate as already suggested for cancer cells by RodríguezEnríquez et al. (2009). If none of the first enzymes of these pathways is saturated with G6P or inhibited in catalytic activity, an increase in the G6P concentration should increase the production rate of UDPGlc, R5P and F6P. Comparison of the calculated total cell volume-specific GLC uptake rate of Rehberg et al. (2013) with measured (in vitro) enzyme activity values of glucose 6-phosphate dehydrogenase and phosphoglucose isomerase by Janke et al. (2011) highlighted that the involved enzymes have a very high capacity for G6P conversion and are therefore presumably not rate limiting. So, it can be assumed that enzymes are unsaturated and that flux rates are correlated with metabolite levels, at least in the upper part of glycolysis. Moreover, intracellular amounts of GLC were always below the detection limit, similarly described for other cell lines by Schmid and Blanch (1992) and Renner et al. (1972). It suggests that MDCK cells modulate the activity of GLUT to achieve desired flux rates and metabolite levels in upper glycolysis, glycogenesis and the pentose phosphate pathway during growth. This corresponds to findings of (Hume et al., 1978; Yasmeen et al., 1977) for rat thymus lymphocytes which show higher flux rates in glycolysis and the pentose phosphate pathway after activation of GLUT with concanavalin-A. The strong influence of GLUT on the glycolytic activity 
is also expected for tumor cells (Eigenbrodt and Glossmann, 1980; Macheda et al., 2005). Also, in yeast cells, the GLUT transport is identified as a major effector of dynamics in glycolysis (Reijenga et al., 2001).

The hexosamines UDPGlcNAc and UDPGalNAc showed an inverse behavior in EpiSerf medium compared to GMEM-Z. In addition, almost no correlation was found with the time series of other metabolites, especially not to glycolytic intermediates, also observed by Barnabé and Butler (2000). In principle, their production depends on the intracellular concentration of $\mathrm{NH}_{4}$, GLN and F6P which, however, our data covers only in parts. However, Ryll et al. (1994) also found the highest level of these hexosamines at the end of the growth phase for various other cell lines.

\section{Dynamics in the lower part of glycolysis}

When the hexoses are split into trioses by entering the lower part of glycolysis, the general picture of the metabolite dynamics is not as clear as in upper glycolysis. It is established that F16BP is an allosteric activator of the pyruvate kinase. A decrease in F16BP reduces the enzyme activity and should lead to higher PEP levels, as observed (Fig. 2e). Intuitively, cells at time of inoculation and end of the cultivation should rest in the same physiological state (stationary growth phase), as long as passaging of the cells from the pre-culture has no effect on intracellular metabolite pools. To check whether medium removal, PBS washing and the transfer into a new well have any influence on the dynamics of intracellular metabolites, we monitored changes in the concentration during such a procedure (data not shown): with medium addition, F16BP as well as PEP returned to the metabolite concentrations before treatment within minutes. Therefore, it is 
likely that metabolites of glycolysis such as F16BP and PEP started with the concentrations of stationary growth phase and have performed an increase and decrease, respectively, during the monitoring gap from 0 to 6 hours, presumably due to a growthdependent modulation of the pathway activity. It indicates that the cells respond with growth metabolism when inoculated in a new well, which is in line with the observed immediate start of total cell volume growth.

3PG is apparently decoupled from the dynamics of PEP in case of the GMEM-Z culture although enolase and phosphoglycerate mutase have a bidirectional catalytic activity. Furthermore, PYR was not increasing due to an F16BP mediated activation of pyruvate kinase in the GMEM-Z culture. Clearly other regulatory influences, related to the optional use of 3PG in serine production and the involvement of PYR in the citric acid cycle as well as in the pyruvate metabolism may play a role. Amino acids such as alanine, glycine, serine and threonine are typically involved in the production or degradation of PYR in MDCK cells (Wahl et al., 2008). The conversion of these amino acids to cytosolic PYR, which results in the production of $\mathrm{NH}_{4}$, may take place in the stationary growth phase of EpiSerf cultures when other substrates such as GLC and GLU were already depleted, and GLN was not taken up. Furthermore, providing an alternative source for intracellular PYR allows sustaining the glycolytic intermediates in the EpiSerf cultures under depletion of extracellular GLC (Fig. 2). Therefore, in these cultures, the flux through glycolysis towards PYR may be comparatively low in stationary growth phase, and even an operation in the opposite direction by means of partial gluconeogenesis with the purpose to ensure the generation of sugar phosphates by the pentose phosphate pathway seems possible. 


\section{Two different parts of the citric acid cycle}

The citric acid cycle is a key part of cell metabolism for biosynthesis and cellular energy generation through respiratory activity. It is fed via anaplerotic reactions such as the conversion of PYR to CIT or oxaloacetate. Another source for citric acid cycle intermediates, such as $\alpha \mathrm{KG}$ and oxaloacetate, is GLU. The total cell volume-specific uptake rate of GLU during the intermediate phase and of its precursor GLN during cell growth was relatively low compared to the rate of GLC (Table 1). Higher GLC than GLN consumption is described for many cell types, such as cancer cells (Baggetto, 1992; Moreno-Sánchez et al., 2007), hybridoma cells (Fitzpatrick et al., 1993), BHK cells (Neermann and Wagner, 1996), and AGE1.HN cells (Niklas et al., 2011). Furthermore, all cell types have in common that only relatively low amounts of GLC derived PYR are transferred in the citric acid cycle, a phenomenon that is widely recognized as Warburg effect (Warburg et al., 1927). Janke et al. (2011) found very low maximum in vitro activities for pyruvate dehydrogenase $\left(18.6 \mathrm{fmol} \mathrm{cell}^{-1} \mathrm{~h}^{-1}\right)$ and pyruvate decarboxylase (52.1 fmol cell $\mathrm{fm}^{-1}$ ) for MDCK cells grown in GMEM-Z. Moreover, a glucose-specific lactate yield coefficient above 2 was found. Accordingly, we assume that fluxes within the citric acid cycle are relatively low compared to glycolysis, as also described by Sidorenko et al. (2008).

Nevertheless, the concerted change in the pools of the citric acid cycle underlines a certain enzyme activity, especially in the lower part from $\alpha \mathrm{KG}$ to SUC, FUM and MAL. The observed peak behavior during total cell volume growth seems to be caused by the growth related changes in GLN and especially in GLU uptake, which starts with the intermediate growth phase (light grey field). In the stationary growth phase, biomass 
synthesis is reduced to a minimum which may explain constant levels of citric acid cycle intermediates in GMEM-Z cell cultures.

Interestingly, the metabolites SUC, FUM and MAL of cells grown in EpiSerf medium showed a second drop in concentrations $(\mathrm{t}>100 \mathrm{~h})$ at the same time when GLU was depleted. Most likely, GLU was a main source for citric acid cycle intermediates during this time period (GLN uptake is zero). This second drop in SUC, FUM and MAL concentrations also influenced the production of ATP, UTP, GTP and CTP (Fig. 6, $\mathrm{t}>$ 100 h). For cells grown in GMEM-Z medium, GLU depletion had no influence on citric acid cycle metabolites or nucleotides as GLC was still taken up. This additionally suggests that intracellular levels of SUC, FUM and MAL are also linked to glycolysis. It is known for many cell lines that the glycolytic carbon flux is mostly directed into the citric acid cycle under extracellular GLC limitation (Cruz et al., 1999; Häggström et al., 1996; Lee et al., 2003; Reitzer et al., 1979; Renner et al., 1972). Therefore GLC is still a source for citric acid cycle intermediates, although the Warburg effect is typically observed during MDCK cell cultivations.

Also the pools of CIT, CAC and ICIT, which represent the upper part of the citric acid cycle, show a link to glycolysis. Firstly, with depletion of GLC in the EpiSerf cell culture, all three metabolites dropped again. Secondly, elevated levels of intracellular PYR of EpiSerf cultures were accompanied with elevated levels of CIT, CAC and ICIT. Sidorenko et al. (2008) suggested that SUC and ICIT are generated from $\alpha \mathrm{KG}$. Furthermore, the authors suggested that the products of both citric acid cycle branches, MAL and CIT, are then used for lipid synthesis and fed into glycolysis as PYR or PEP, respectively, which is also found for AGE1.HN cells at initial times of cultivation (Niklas 
et al., 2011). So, CIT is withdrawn from the citric acid cycle, which suggests the presence of a truncated citric acid cycle reviewed by Baggetto (1992) and Moreno-Sánchez et al. (2007). Moreover, this additional feed into glycolysis may result in a glucose-specific lactate yield coefficient that is above the theoretical maximum of 2 (Fitzpatrick et al., 1993; Moreno-Sánchez et al., 2007; Reitzer et al., 1979), also observed by Genzel et al. (2010) for MDCK cells in GMEM-Z. Nevertheless, as the levels of CIT, CAC and ICIT seem to be correlated with the PYR pool, it appears unlikely that the upper and lower citric acid cycle is completely decoupled. The connecting enzymes pyruvate dehydrogenase and citrate synthase show a very low activity for metabolite conversion (Janke et al., 2011) which, however, could still be high enough to allow for the found relation of CIT and PYR.

\section{The mutual influence of metabolism and nucleotides}

The adenosine, guanosine, cytidine and uridine-based nucleotides showed large changes in their concentration but mostly in a concerted way. Dynamics of ATP and GTP were very similar and showed a negative correlation with their diphosphatic and monophosphatic counterparts. The energy charge mostly followed the dynamics of ATP due to its much higher abundance compared to ADP and AMP. Assuming a adenosine conservation nicely explains the observed dynamics of the three nucleotides. Calculation reveals, however, that the increase in ATP concentration is $66 \%$ higher than the decrease in ADP and AMP (Fig. S1). Thus, the total adenosine pool is not constant, which was similarly found for yeast cells after onset of cell growth due to a GLC pulse (Loret et al., 2007; Verma et al., 2013). The same holds for the guanosines and indicates the interplay 
of consumption and de novo synthesis of nucleosides during the different cell growth phases as they are essential for nucleic acid synthesis (Traut, 1994). Regarding the dynamics, this raises the question to what extent the metabolism is subject to adenylate control (Atkinson, 1969) and how energy-rich nucleotides serve as a mediator in cases where the demand exceeds the supply, thereby adjusting the activity of the biosynthesis machinery. As an example, the phosphofructo kinase as well as the citrate cleavage enzyme are both assumed to be controlled by the ATP/AMP ratio, a regulatory mechanism that is comprehensively described by Atkinson and Walton (1967).

To discuss this in more detail, we again assume that all metabolites and nucleotides start with initial values similar to the levels of the stationary growth phase (about $t=200 \mathrm{~h}$ in GMEM-Z cultures). Thus, the ATP pool may have dropped fast at initial times of cultivation due to the onset of total cell volume growth, which requires high amounts of ATP. Although the time scale and the shape of the decrease remain to be elucidated, it seems that the decrease in ATP concentration due to cell volume growth poses an interesting analogy to a substrate pulse in yeast cell cultures (Verma et al., 2013). Afterwards the ATP pool is replenished slowly, due to the high uptake of GLC and GLN which yield ATP from ADP during breakdown in glycolysis and citric acid cycle. In this scenario, the ATP and GTP pools reflect the balance between the cellular energy supply by metabolism and the demand for the biosynthesis machinery. Consequently, resting cells (stationary growth phase) have higher intracellular concentrations of both nucleotides than growing cells (Figure 6a, d). Inspection of the ATP amount per cell pointed in the opposite direction where resting cells have lower concentration than growing cells which is in agreement to measurements of Traut (1994) for tumor cells. 
However, such a role as mediator between cellular supply and demand could neither be clearly observed for precursors of biosynthesis, such as R5P, UDPNAcGlc, UDPNAcGln nor for other metabolites monitored in our study. Another observation is that a possible activation of phosphofructokinase by low ATP levels coincides with comparatively high concentrations of the substrate F6P. Hence, adenylate control of phosphofructo kinase may be superimposed by the large, GLUT-mediated, carbon flux through glycolysis with generally elevated metabolite levels in upper glycolysis. Furthermore, with the depletion of GLC and GLU in the supernatant of EpiSerf cultures and a negligible GLN uptake the pools of ATP and GTP decreased. In particular, dynamics of ATP seemed to correlate with the drop of citric acid cycle intermediates of the lower branch $(t>100 \mathrm{~h})$. However, the remaining citric acid cycle metabolites were not fully consumed to increase the ATP level and, hence, adenylate control was also not obvious during GLC and GLU limitation. In summary, neither during substrate limitation nor during cell growth the levels of nucleotides were kept constant by metabolism. Therefore, it appears reasonable to assume that the importance of biomass growth as well as a cellular response to substrate limitation may overcome the necessity to maintain an adequate nucleotide pool, at least on the time scale of days. In the context of a supply and demand scenario, we suggest that the dynamics of UTP and CTP is mainly driven by a production rate during cell growth exceeding cellular demands.

\section{How do different media and progression through cell growth phases finally affect intracellular metabolite dynamics?}


Without question, extracellular substrates can influence cell growth and uptake rates which in turn should have an impact on intracellular metabolite concentrations in the metabolic network. In particular, we observed elevated levels of intracellular PYR as well as the elevated levels of CIT, ICIT and CAC at initial times of cultivation in EpiSerf medium. Also slightly lower levels in upper glycolysis of EpiSerf cultures were observed. Valley et al. (1999) and Ryll et al. (1994) proposed that UDP-GalNAc and UDP-GlcNAc production depend on extracellular ammonium levels and may thus be changed in different media. Furthermore, larger changes in metabolic functioning can be expected when cells are adapted to a new medium, as shown for $\mathrm{CHO}$ cells by Dietmair et al. (2012). Apart from these issues, the intracellular metabolite dynamics were not affected significantly by changes in extracellular substrate concentrations of GMEM-Z and EpiSerf medium. Obviously, both media provide sufficient amounts of the main substrates GLC, GLN and GLU and other compounds to allow for a similar cell growth behavior. Rather, we find that the upper part of glycolysis, glycogenesis and the pentose phosphate pathway seem to be strongly influenced by a growth phase-dependent GLC uptake, that changes in metabolite concentrations in the lower part of glycolysis indicate a possible feed forward regulation by F16BP, and that metabolite dynamics of lower citric acid cycle depend mostly on the consumption of GLN and GLU. Also, the levels of nucleotides showed similar dynamics in both media and seem to act as mediator between cellular demand and supply while their role as regulators of central carbon metabolism could not be observed. Furthermore, the effects of substrate limitations, observed during stationary growth of the EpiSerf cultures, may not be different to limitations in GMEM-Z and are, of course, very specific scenarios of cell cultivation. 
Ultimately, we conclude that MDCK cells derived from the same pre-culture and without limitation in nutrient levels show similar regulatory principles for glucose and glutamine/glutamate metabolism, although inoculated in two different media. The identified interplay of growth phase-dependent uptake rates and regulatory function of key enzymes clearly improves our understanding of metabolism and also promotes a deeper, model-based analysis to further elucidate the metabolic regulation and the resulting energetic and biosynthetic supply of the cell.

\section{Bibliography:}

Atkinson DE. 1969. Regulation of Enzyme Function. Annual Review of Microbiology 23:47-\&.

Atkinson DE, Walton GM. 1967. Adenosine triphosphate conservation in metabolic regulation. Rat liver citrate cleavage enzyme. J Biol Chem 242(13):3239-41.

Baggetto LG. 1992. Deviant energetic metabolism of glycolytic cancer cells. Biochimie 74(11):959-74.

Ballard FJ. 1970. Adenine nucleotides and the adenylate kinase equilibrium in livers of foetal and newborn rats. Biochem J 117(2):231-235.

Barnabé N, Butler M. 2000. The effect of glucose and glutamine on the intracellular nucleotide pool and oxygen uptake rate of a murine hybridoma. Cytotechnology 34(1-2):47--57.

Bock A, Sann H, Schulze-Horsel J, Genzel Y, Reichl U, Möhler L. 2009. Growth behavior of number distributed adherent MDCK cells for optimization in microcarrier cultures. Biotechnol Prog 25(6):1717--1731.

Cruz HJ, Ferreira AS, Freitas CM, Moreira JL, Carrondo MJ. 1999. Metabolic responses to different glucose and glutamine levels in baby hamster kidney cell culture. Appl Microbiol Biotechnol 51(5):579--585.

Dietmair S, Hodson MP, Quek L-E, Timmins NE, Chrysanthopoulos P, John SS, Gray P, Nielsen LK. 2012. Metabolite profiling of CHO cells with different growth characteristics. Biotechnol Bioeng.

Eigenbrodt E, Glossmann H. 1980. Glycolysis - one of the keys to cancer. Trends Pharmacol Sci 1(9):240-245.

Erlinger SU, Saier MH. 1982. Decrease in protein content and cell volume of cultured dog kidney epithelial cells during growth. In Vitro 18(3 Pt 1):196--202.

Fitzpatrick L, Jenkins HA, Butler M. 1993. Glucose and glutamine metabolism of a murine B-lymphocyte hybridoma grown in batch culture. Appl Biochem Biotechnol 43(2):93--116. 
Genzel Y, Behrendt I, König S, Sann H, Reichl U. 2004. Metabolism of MDCK cells during cell growth and influenza virus production in large-scale microcarrier culture. Vaccine 22(17-18):2202--2208.

Genzel Y, Dietzsch C, Rapp E, Schwarzer J, Reichl U. 2010. MDCK and Vero cells for influenza virus vaccine production: a one-to-one comparison up to lab-scale bioreactor cultivation. Appl Microbiol Biotechnol 88(2):461--475.

Genzel Y, Fischer M, Reichl U. 2006. Serum-free influenza virus production avoiding washing steps and medium exchange in large-scale microcarrier culture. Vaccine 24(16):3261--3272.

Genzel Y, Reichl U. 2007. Methods in biotechnology: animal cell biotechnology: Vaccine production-state of the art and future needs in upstream processing, Humana Press Inc., Totowa.

Genzel Y, Ritter JB, König S, Alt R, Reichl U. 2005. Substitution of glutamine by pyruvate to reduce ammonia formation and growth inhibition of mammalian cells. Biotechnol Prog 21(1):58--69.

Glacken MW, Adema E, Sinskey AJ. 1988. Mathematical descriptions of hybridoma culture kinetics: I. Initial metabolic rates. Biotechnol Bioeng 32(4):491--506.

Häggström L, Ljunggren J, Ohman L. 1996. Metabolic engineering of animal cells. Ann N Y Acad Sci 782:40--52.

Hume DA, Radik JL, Ferber E, Weidemann MJ. 1978. Aerobic glycolysis and lymphocyte transformation. Biochem J 174(3):703--709.

Janke R, Genzel Y, Handel N, Wahl A, Reichl U. 2011. Metabolic adaptation of MDCK cells to different growth conditions: effects on catalytic activities of central metabolic enzymes. Biotechnol Bioeng 108(11):2691-704.

Janke R, Genzel Y, Wahl A, Reichl U. 2010. Measurement of key metabolic enzyme activities in mammalian cells using rapid and sensitive microplate-based assays. Biotechnol Bioeng 107(3):566--581.

Kallel H, Jouini A, Majoul S, Rourou S. 2002. Evaluation of various serum and animal protein free media for the production of a veterinary rabies vaccine in BHK-21 cells. J Biotechnol 95(3):195--204.

Lee YY, Yap MGS, Hu W-S, Wong KTK. 2003. Low-glutamine fed-batch cultures of 293-HEK serum-free suspension cells for adenovirus production. Biotechnol Prog 19(2):501--509.

Levine AJ, Puzio-Kuter AM. 2010. The control of the metabolic switch in cancers by oncogenes and tumor suppressor genes. Science 330(6009):1340--1344.

Levine KB, Cloherty EK, Hamill S, Carruthers A. 2002. Molecular determinants of sugar transport regulation by ATP. Biochemistry 41(42):12629--12638.

Loret MO, Pedersen L, François J. 2007. Revised procedures for yeast metabolites extraction: application to a glucose pulse to carbon-limited yeast cultures, which reveals a transient activation of the purine salvage pathway. Yeast 24(1):47-60.

Macheda ML, Rogers S, Best JD. 2005. Molecular and cellular regulation of glucose transporter (GLUT) proteins in cancer. J Cell Physiol 202(3):654--662.

Mckeehan W. 1982. Glycolysis, glutaminolysis and cell-proliferation. Cell Biology International Reports 6(7):635--650.

Moreno-Sánchez R, Rodríguez-Enríquez S, Marín-Hernández A, Saavedra E. 2007. Energy metabolism in tumor cells. FEBS J 274(6):1393--1418. 
Neermann J, Wagner R. 1996. Comparative analysis of glucose and glutamine metabolism in transformed mammalian cell lines, insect and primary liver cells. $\mathbf{J}$ Cell Physiol 166(1):152--169.

Nelson CA, Wang JQ, Leav I, Crane PD. 1996. The interaction among glucose transport, hexokinase, and glucose-6-phosphatase with respect to 3H-2-deoxyglucose retention in murine tumor models. Nucl Med Biol 23(4):533--541.

Nielsen LK, Reid S, Greenfield PF. 1997. Cell cycle model to describe animal cell size variation and lag between cell number and biomass dynamics. Biotechnol Bioeng 56(4):372--379.

Niklas J, Schräder E, Sandig V, Noll T, Heinzle E. 2011. Quantitative characterization of metabolism and metabolic shifts during growth of the new human cell line AGE1.HN using time resolved metabolic flux analysis. Bioprocess Biosyst Eng 34(5):533--545.

Purich DL, Fromm HJ. 1972. Studies on Factors Influencing Enzyme Responses to Adenylate Energy Charge. Journal of Biological Chemistry 247(1):249-\&.

Rehberg M, Ritter JB, Genzel Y, Flockerzi D, Reichl U. 2013. The relation between growth phases, cell volume changes and metabolism of adherent cells during cultivation. J Biotechnol 164(4):489-99.

Reijenga KA, Snoep JL, Diderich JA, van Verseveld HW, Westerhoff HV, Teusink B. 2001. Control of glycolytic dynamics by hexose transport in Saccharomyces cerevisiae. Biophys J 80(2):626--634.

Reitzer LJ, Wice BM, Kennell D. 1979. Evidence that glutamine, not sugar, is the major energy source for cultured HeLa cells. J Biol Chem 254(8):2669--2676.

Renner ED, Plagemann PG, Bernlohr RW. 1972. Permeation of glucose by simple and facilitated diffusion by Novikoff rat hepatoma cells in suspension culture and its relationship to glucose metabolism. J Biol Chem 247(18):5765--5776.

Ritter J. 2010. Charakterisierung tierischer Zellkulturen anhand einer Quantifizierung intrazellulärer Metaboliten aus dem Zentralstoffwechsel: Dissertation. Otto-vonGuericke University Magdeburg.

Ritter JB, Genzel Y, Reichl U. 2006. High-performance anion-exchange chromatography using on-line electrolytic eluent generation for the determination of more than 25 intermediates from energy metabolism of mammalian cells in culture. $\mathrm{J}$ Chromatogr B Analyt Technol Biomed Life Sci 843(2):216-26.

Ritter JB, Genzel Y, Reichl U. 2008. Simultaneous extraction of several metabolites of energy metabolism and related substances in mammalian cells: optimization using experimental design. Anal Biochem 373(2):349-69.

Ritter JB, Wahl AS, Freund S, Genzel Y, Reichl U. 2010. Metabolic effects of influenza virus infection in cultured animal cells: Intra- and extracellular metabolite profiling. BMC Syst Biol 4:61.

Rodríguez-Enríquez S, Marín-Hernández A, Gallardo-Pérez JC, Moreno-Sánchez R. 2009. Kinetics of transport and phosphorylation of glucose in cancer cells. J Cell Physiol 221(3):552--559.

Ryll T, Valley U, Wagner R. 1994. Biochemistry of growth inhibition by ammonium ions in mammalian cells. Biotechnol Bioeng 44(2):184--193. 
Schaub J, Reuss M. 2008. In vivo dynamics of glycolysis in Escherichia coli shows need for growth-rate dependent metabolome analysis. Biotechnol Prog 24(6):1402-1407.

Schmid G, Blanch HW. 1992. Extra- and intracellular metabolite concentrations for murine hybridoma cells. Appl Microbiol Biotechnol 36(5):621--625.

Sellick CA, Croxford AS, Maqsood AR, Stephens G, Westerhoff HV, Goodacre R, Dickson AJ. 2011. Metabolite profiling of recombinant CHO cells: designing tailored feeding regimes that enhance recombinant antibody production. Biotechnol Bioeng 108(12):3025--3031.

Sidorenko Y, Wahl A, Dauner M, Genzel Y, Reichl U. 2008. Comparison of metabolic flux distributions for MDCK cell growth in glutamine- and pyruvate-containing media. Biotechnol Prog 24(2):311-20.

Suarez RK, Moyes CD. 2012. Metabolism in the age of 'omes'. J Exp Biol 215(Pt 14):2351--2357.

Sussman I, Erecińska M, Wilson DF. 1980. Regulation of cellular energy metabolism: the Crabtree effect. Biochim Biophys Acta 591(2):209--223.

Takata K, Iizuka A, Suzuki T, Matsuzaki T, Sugawara M, Shin B, Nomingerel T, Shinoda Y. 1999. Sugar transporters in polarized epithelial cells. Acta Histochem Cytoc 32(1):53-58.

Thorens B. 1993. Facilitated glucose transporters in epithelial cells. Annu Rev Physiol 55:591--608.

Traut TW. 1994. Physiological concentrations of purines and pyrimidines. Mol Cell Biochem 140(1):1--22.

Valley U, Nimtz M, Conradt HS, Wagner R. 1999. Incorporation of ammonium into intracellular UDP-activated $\mathrm{N}$-acetylhexosamines and into carbohydrate structures in glycoproteins. Biotechnol Bioeng 64(4):401--417.

Verma M, Zakhartsev M, Reuss M, Westerhoff HV. 2013. 'Domino' systems biology and the 'A' of ATP. Biochim Biophys Acta 1827(1):19--29.

Wahl A, Sidorenko Y, Dauner M, Genzel Y, Reichl U. 2008. Metabolic flux model for an anchorage-dependent MDCK cell line: characteristic growth phases and minimum substrate consumption flux distribution. Biotechnol Bioeng 101(1):135-52.

Warburg O, Wind F, Negelein E. 1927. The metabolism of tumors in the body. J Gen Physiol 8(6):519--530.

Wu R, Racker E. 1959. Regulatory mechanisms in carbohydrate metabolism. III. Limiting factors in glycolysis of ascites tumor cells. J Biol Chem 234(5):1029-1035.

Yasmeen D, Laird AJ, Hume DA, Weidemann MJ. 1977. Activation of 3-O-methylglucose transport in rat thymus lymphocytes by concanavalin A. Temperature and calcium ion dependence and sensitivity to puromycin but to cycloheximide. Biochim Biophys Acta 500(1):89--102.

Young CD, Lewis AS, Rudolph MC, Ruehle MD, Jackman MR, Yun UJ, Ilkun O, Pereira R, Abel ED, Anderson SM. 2011. Modulation of Glucose Transporter 1 (GLUT1) Expression Levels Alters Mouse Mammary Tumor Cell Growth In Vitro and In Vivo. PLoS One 6(8):e23205.

Zhang JZ, Behrooz A, Ismail-Beigi F. 1999. Regulation of glucose transport by hypoxia. Am J Kidney Dis 34(1):189--202. 
Table 1. Total cell volume-specific uptake rate of substrates and release rate of metabolites in two different media. Rates are depicted as mean and standard deviation of

\begin{tabular}{cccccc}
\hline & ${ }^{\mathrm{a}} \mathrm{r}_{\mathrm{GLC}}\left(\frac{m m o l}{L h}\right)$ & ${ }^{\mathrm{a}} \mathrm{r}_{\mathrm{GLN}}\left(\frac{m m o l}{L h}\right)$ & ${ }^{\mathrm{b}} \mathrm{r}_{\mathrm{GLU}}\left(\frac{m m o l}{L h}\right)$ & ${ }^{\mathrm{a}} \mathrm{r}_{\mathrm{LAC}}\left(\frac{m m o l}{L h}\right)$ & ${ }^{\mathrm{a}} \mathrm{r}_{\mathrm{NH} 4}\left(\frac{m m o l}{L h}\right)$ \\
GMEM-Z & $-187 \pm 70$ & $-16 \pm 6$ & $-12.4 \pm 1$ & $409 \pm 73$ & $8 \pm 1$ \\
EpiSerf & $-167 \pm 20$ & $-7 \pm 5$ & $-8 \pm 2$ & $385 \pm 21$ & $12 \pm 1$ \\
\hline
\end{tabular}

three independent cultivations taking into account evaporation and glutamine decomposition.

${ }^{a}$ calculated for the time interval 0-48 h.

${ }^{\mathrm{b}}$ calculated for the time interval 35-62 h (GMEM-Z) / 61-132 h (EpiSerf) 

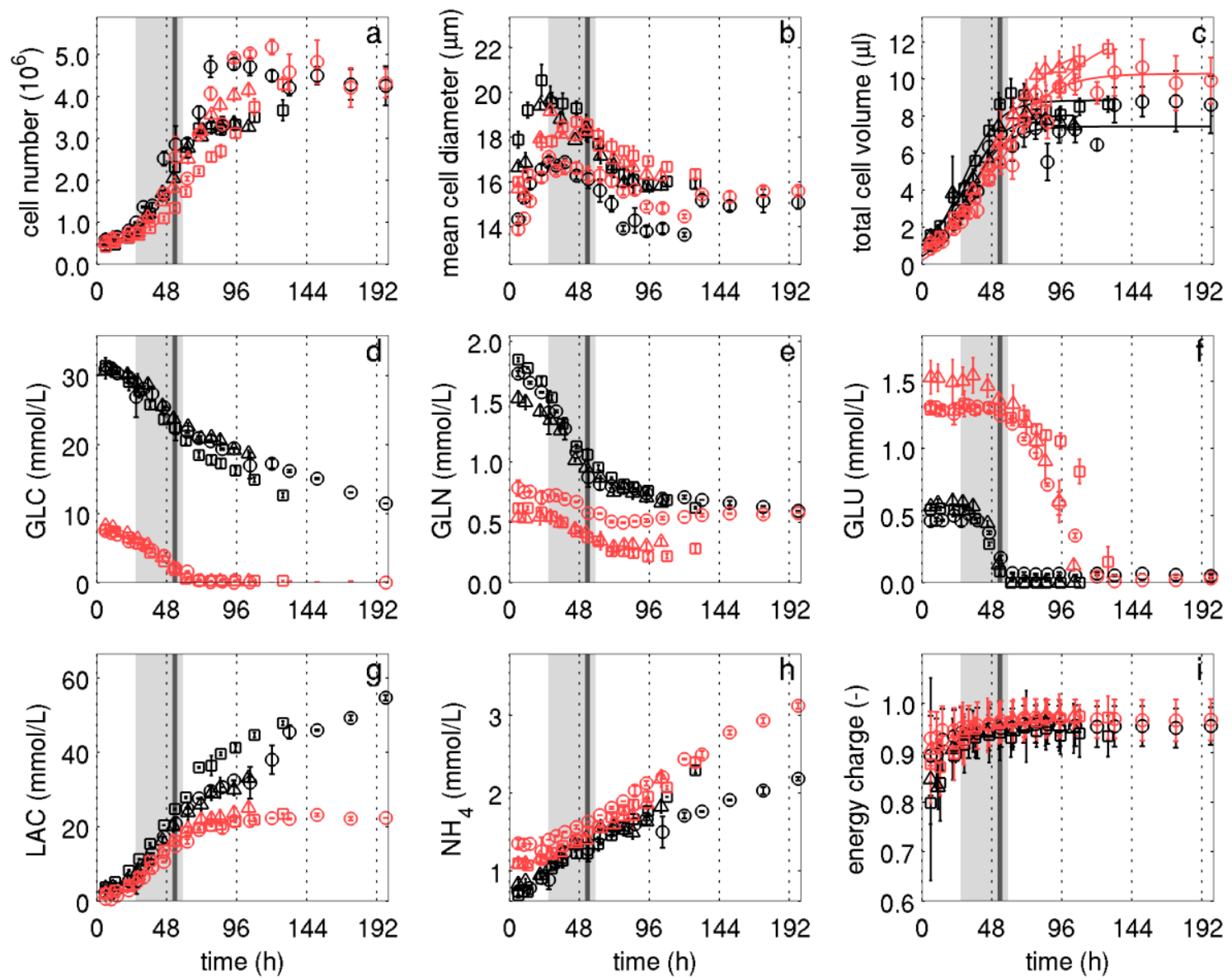

Fig. 1 Growth of adherent MDCK cells in 6-well plates with either GMEM-Z (black) medium or EpiSerf (red) medium. Time series of the cell number (a), the mean cell diameter (b), the total cell volume (c), the extracellular metabolites glucose (d), glutamine (e), glutamate (f), lactate (g), and ammonium (h) were measured in three independent experiments marked with symbols $\Delta, \circ$ and $\square$ (mean and standard deviation of three wells). The energy charge (i) is calculated from the intracellular concentrations of ATP, ADP and AMP (standard deviation derived with law of error propagation). Light grey field between $1-2.5$ days of cultivation illustrates the interval of $5 \%$ to $95 \%$ growth inhibition according to Rehberg et al. (2013); black bar indicates the cease of total cell volume growth after 2 days. 

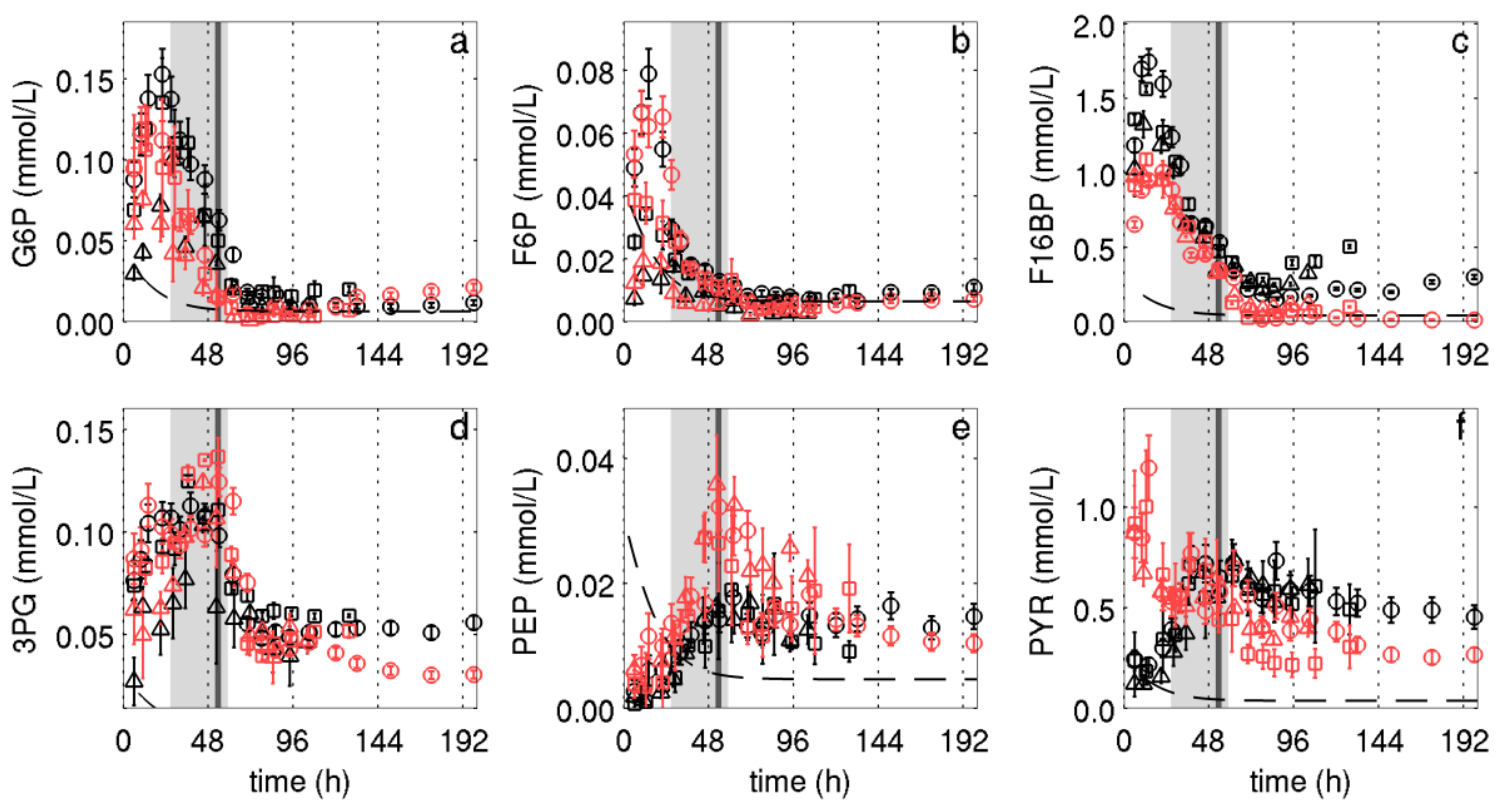

Fig. 2 Dynamics of glycolytic intermediates during cultivation of adherently growing MDCK cells in GMEM-Z and EpiSerf. The upper part of glycolysis with glucose 6phosphate (a), fructose 6-phosphate (b), fructose 1,6-bisphosphate and the lower part of glycolysis with glyceraldehyde 3-phosphate (d), phosphoenolpyruvate (e) and pyruvate (f) are shown in the color code of Fig. 1. The limit of quantification is shown as dashed black line (- -). Light grey field between $1-2.5$ days of cultivation illustrates the interval of $5 \%$ to $95 \%$ growth inhibition according to Rehberg et al. (2013); black bar indicates the cease of total cell volume growth after 2 days. 

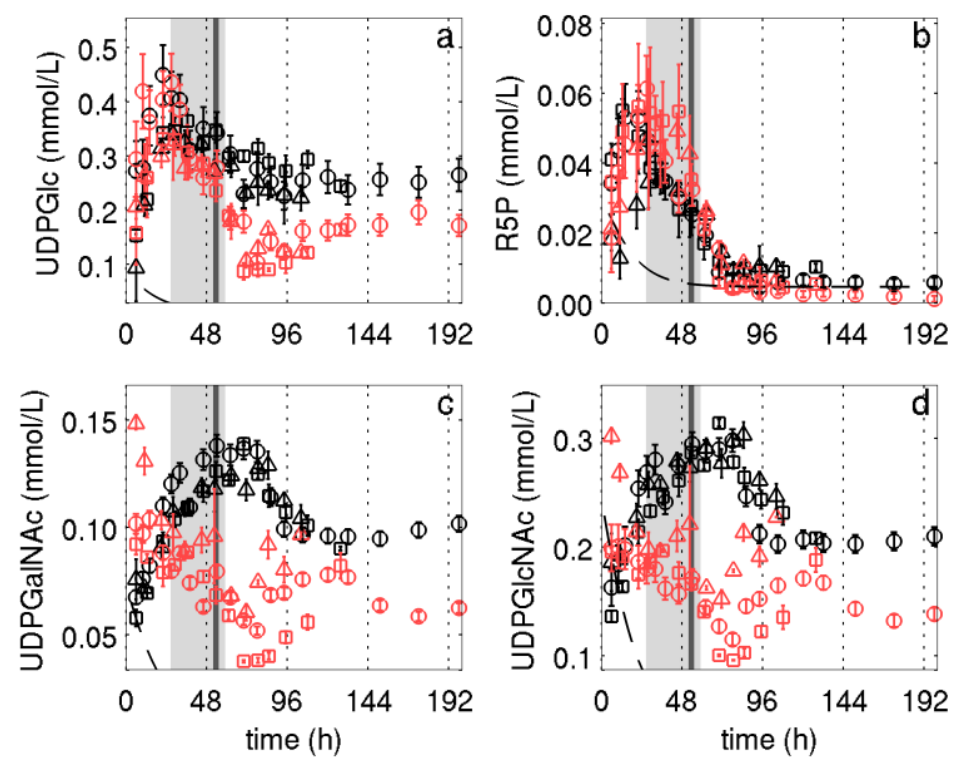

Fig. 3 Dynamics of intermediates of glycogenesis, pentose phosphate pathway and hexosamine biosynthesis pathway during cultivation of adherently growing MDCK cells in GMEM-Z and EpiSerf. Uridine diphsophate glucose (a), ribose 5-phosphate (b), uridine diphosphate N-acetylglucosamine (c) and uridine diphosphate $\mathrm{N}$ acetylgalactosamine (d) are shown in the color code of Fig. 1. The limit of quantification is shown as dashed black line (- -). Light grey field between 1-2.5 days of cultivation illustrates the interval of $5 \%$ to $95 \%$ growth inhibition according to Rehberg et al. (2013); black bar indicates the cease of total cell volume growth after 2 days. 

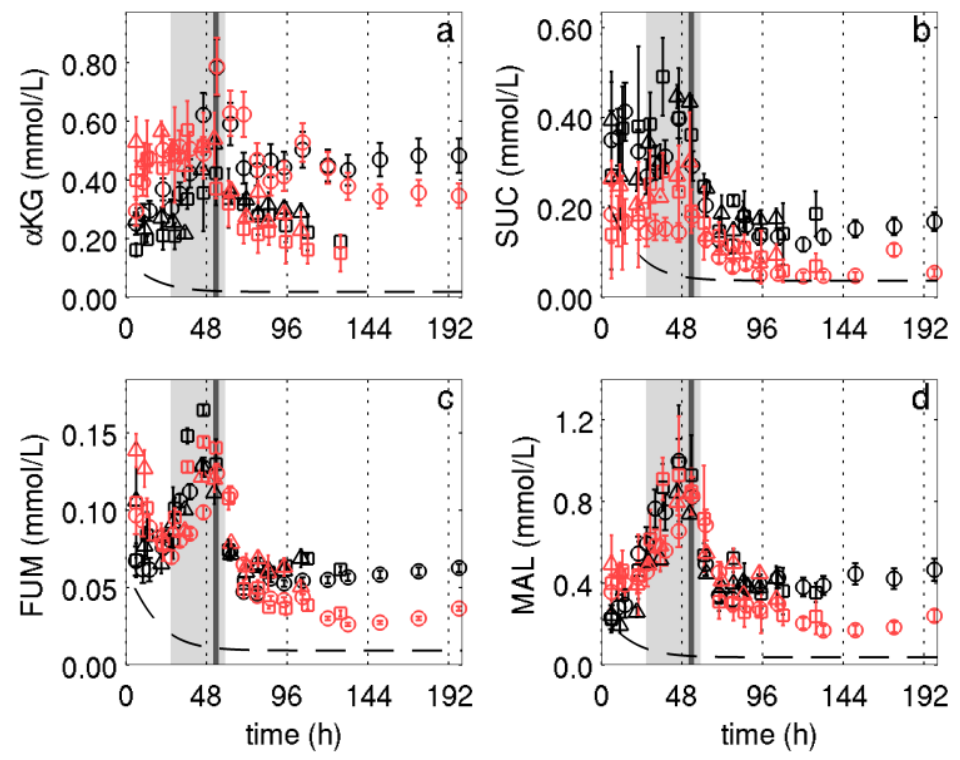

Fig. 4 Dynamics of lower citric acid cycle intermediates during cultivation of adherently growing MDCK cells in GMEM-Z medium and EpiSerf medium. Time series of $\alpha$ ketoglutarate (a), succinate (b), fumarate (c) and malate (d) are shown in the color code of Fig. 1. The limit of quantification is shown as dashed black line (- -). Light grey field between 1-2.5 days of cultivation illustrates the interval of $5 \%$ to $95 \%$ growth inhibition according to Rehberg et al. (2013); black bar indicates the cease of total cell volume growth after 2 days. 

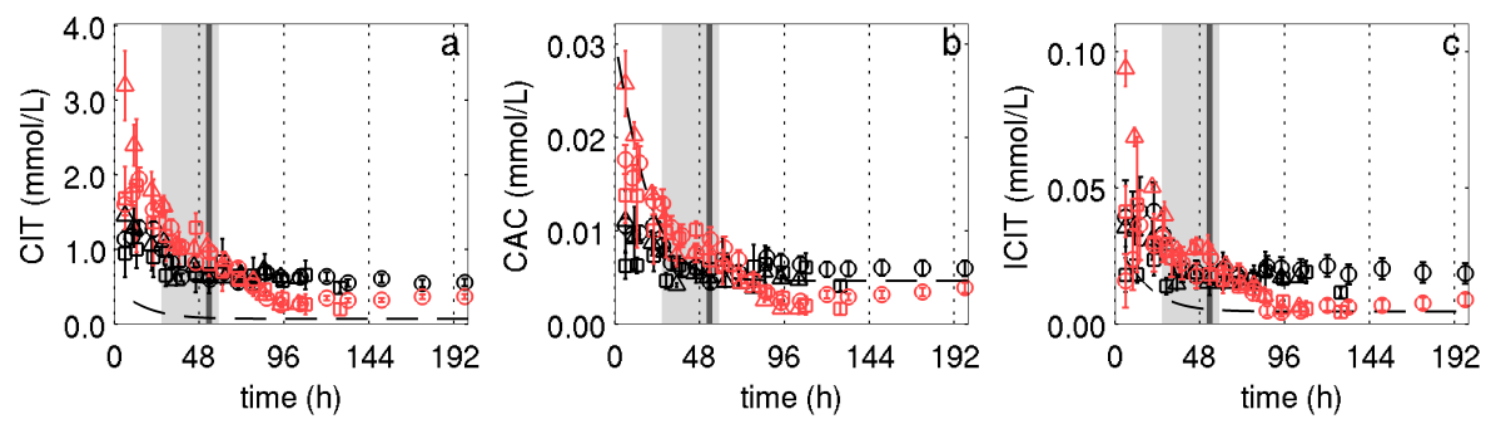

Fig. 5 Dynamics of upper citric acid cycle intermediates during cultivation of adherently growing MDCK cells in GMEM-Z medium and EpiSerf medium. Time series of citrate (a), cis-aconitate (b) and isocitrate (c) are shown in the color code of Fig. 1. The limit of quantification is shown as dashed black line (- -). Light grey field between 1-2.5 days of cultivation illustrates the interval of $5 \%$ to $95 \%$ growth inhibition according to Rehberg et al. (2013); black bar indicates the cease of total cell volume growth after 2 days. 

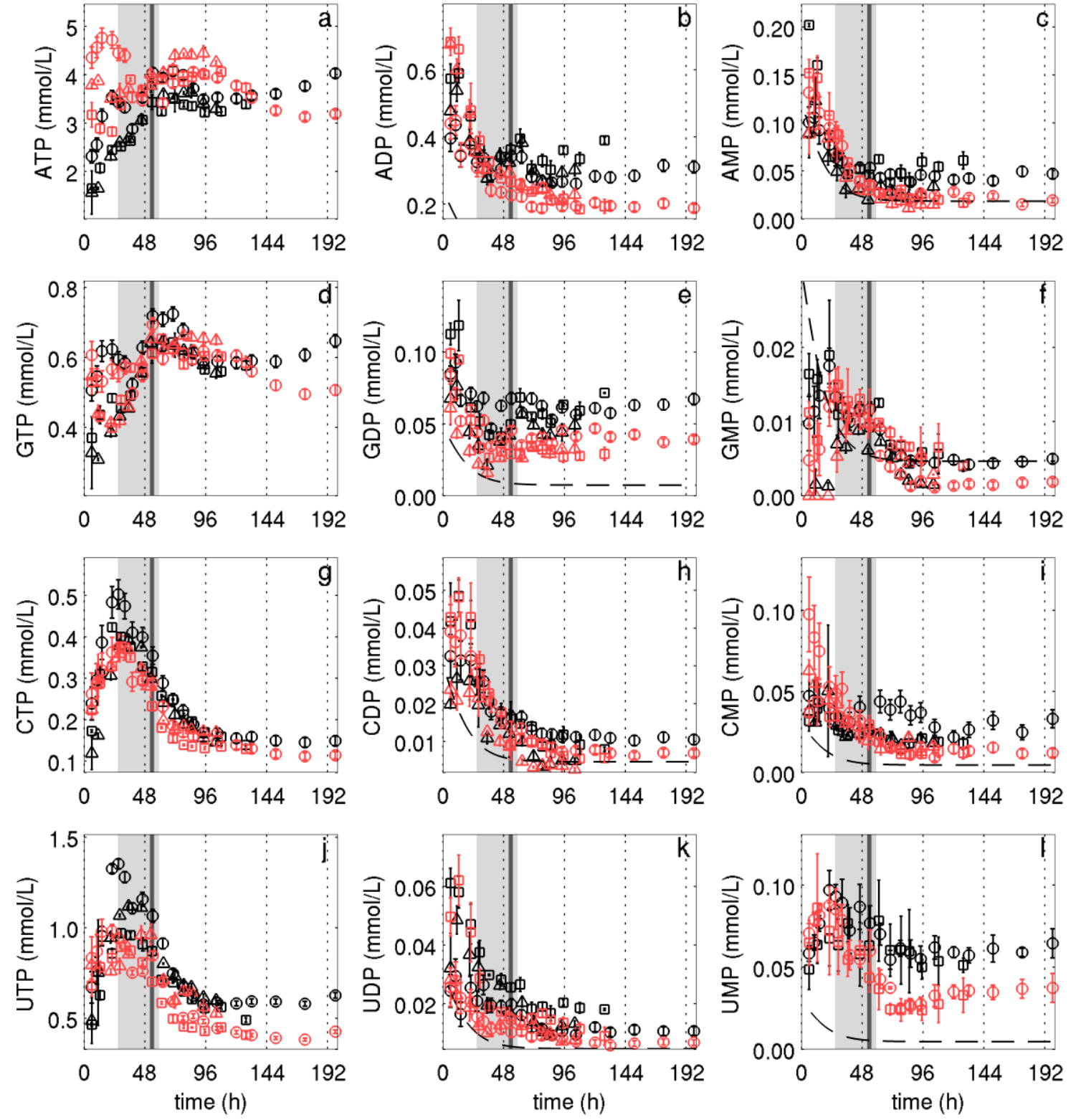

Fig. 6 Dynamics of nucleosides with monophosphates (MP), diphosphates (DP) and triphosphates (TP) during cultivation of adherently growing MDCK cells in GMEM-Z medium and EpiSerf medium. Time series of adenosines (a-c), guanosines (d-f), cytidines (g-i) and uridines (j-l) are shown in the color code of Fig. 1. The limit of quantification is shown as dashed black line (- -). Light grey field between 1-2.5 days of cultivation 
illustrates the interval of $5 \%$ to $95 \%$ growth inhibition according to Rehberg et al. (2013); black bar indicates the cease of total cell volume growth after 2 days. 